\title{
Studies on EMI Shielding using Conducting Composites Coatings
}

\author{
Noor Saba \\ $4^{\text {th }}$ sem M. Tech in Power System Engineering, \\ Ghousia College of Engineering. \\ Ramanagaram - Karnataka.
}

Mr. Amanulla

Assistant Professor,

Department of Electrical \& Electronics,

Ghousia College of Engineering,

Ramanagaram - Karnataka.

\author{
Dr. K. G. Manjunatha \\ Professor, Head of Chemistry Department, \\ Ghousia College of Engineering, \\ Bangalore - Karnataka. \\ Dr. Reavanasiddappa. M. \\ Professor, Head of Chemistry Department, \\ PESU Electronic City Campus, \\ Bangalore - Karnataka.
}

\begin{abstract}
This paper is aimed at synthesis of conducting polymers (CP's) like Polypyrrole (PPY) and polyaniline (PANI) through chemical oxidation with different dopants has been carried out. It is then mixed with various host polymer matrix system like PMMA (poly methyl methacrylate), Epoxy to prepare conducting composites it is observed that Shielding effectiveness is directly depend on conductivity of the composites. Shielding effectiveness (SE) is measured by passing microwave radiations between 2 to $3 \mathrm{GHz}$. The composites prepared by PPY doped with Dodecyl benzene sulfonic acid (DDBSA) has shown highest shielding effectiveness of $10.59 \mathrm{~dB}$.
\end{abstract}

Keywords-Poly methyl methacrylate, polianiline, polypyrrole, epoxy, shielding effectiveness, Conducting polymers.

\section{INTRODUCTION.}

Electromagnetic interference (EMI) additionally called radio radio frequency ( $\mathrm{RFI}$ ) when in radio range is an unsettle domination assembled by an apparent that controls an electrical circuit by electromagnetic enlistment or electrostatic coupling. The aggravation may debase the exhibition of circuit or even avert it from useable. On facts of an information way, this smack can go from increment in blunder cost to a complete loss of the information. Both artificial and common origin fabricate vary electrical flows and voltages that can cause EMI: Ignition structures, cell system of cell extensions, lightning, sunlight based flares and auroras.

EMI oftentimes influences AM radios it likewise influences cell extensions, FM radios and Television just as perceptions for radio space science and barometrical science. The expanding intricacy of electronic gadgets/framework in structure higher pressing thickness for snappy reaction has come about in EMI. EMI protecting is accepting expanding constriction in electrical and hardware and correspondence ventures in view of gadget getting progressively delicate, thick and plentiful. The electromagnetic impedance between the gadgets and circuits has been generally read for the commotion assimilation and electromagnetic obstruction concealment of present day electronic gadgets.

In a request to decrease the EMI between signal lines, segments and circuit in radio frequency (RF) area the attractive films and composite as an EMI silencer have been generally evolved and applied to the hardware. The vast majority of the polymer composite with leading fillers, for example, round particles and chips and filaments, textures has been generally utilized for EMI assimilation and protecting at war-field and far-field district. The consequences of EMI can be diminished by situating protecting substances between the wellspring of EM area and touchy segments (portable, PC, TV, clinical hardware, airplane, radars and so on).

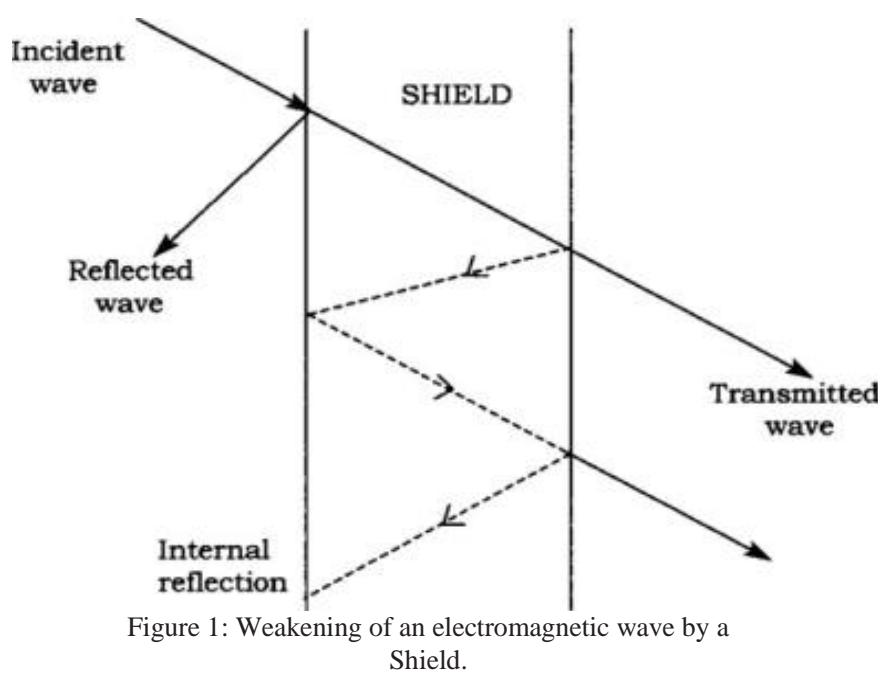

Different EMI protecting materials have been created to wipe out undesirable EM radiation just as to ensure neighboring parts in Electronic gadgets. Not with standing high EMI, protecting execution, simple preparing and light loads are among the solution boundaries required for matter in many rising regions like aviation, airplane, and vehicles. 
Two types materials including:

\section{Permeable foam material}

\section{Conductive polymer composites (CPCs)}

Conductive fillers containing permeable frothed metal build composites in attendance great protecting adequacy they also have significant downside of moderately high densities. While conductive polymer composites (CPCs) strengthened with conductive material polyaniline, polypyrrole, polythiophene, convey exceptional protecting viability relying upon their characteristic properties, for example, Di-electric consistent, Electrical conductivities.

\section{PREPARATION OF CONDUCTIVE COMPOSITES.}

\section{A. Preparation of PMMA Gel.}

PMMA (Poly methyl methacrylate) polymer obtained in solid form and dissolved in an organic solvent such as acetone till highly viscous liquid is formed. This is used as a host polymer which holds the ingredient that is added to it.

\section{B. Synthesis of Conducting Polymer.}

Polypyrrole and polyaniline in conducting form is synthesized by taking pyrrole and aniline as a monomer. Both the monomer are taken in an organic solvent to that dopants such as HCL, PTSA, BSA, CCL4, DDBSA, are taken as two molar concentration to that required quantity of oxidation like ammonium per sulphate is added as an oxidant. This solution is added to the monomer slowly with continuous stirring by keeping the mixture on a magnetic stirrer reaction process is carried for two hours with continuous stirring in room temperature. Then the mixture is filtered and washed with distilled water and then with methanol and finally with acetone. The filter cake is transferred to a china dish and then kept in an oven at 80 degree Celsius for drying about 12 hours. The dried cake is transferred to mortar and grown to a fine powder. Polypyrrole is obtained in the form of black powder and polyaniline is obtained as a green powder. Both the product is stored in an air tight container.

\section{EXPERIMENTAL}

\section{A. Preparation of Conductive Composites Coatings.}

\section{- PMMA.}

Previously prepared PMMA is weighed in a glass container to that $1 \%$ weight ratio of the conducting polymers are added with few drops of castor oil is added to increase the flexibility in the film. The mixture is thoroughly mixed without forming air bubbles. It is then poured on to a acrylic based material which are cut into dimension $3.4 \times 7.3 \mathrm{~cm}$ size. It is then placed in a desiccator for 24 hours. During this time the solvent slowly evaporate leaving behind a coating of conductive composite.

Poly methyl methacrylate (PMMA) is also called by a commercial name Bakelite it is a linear polymer synthesize by addition polymerization process in bulk polymerization method using peroxide as solvent with methacrylate as monomer.

- DGBA.

Epoxy resin of the composition of DGBA (Di glycerol bis phenol-A) is taken in liquid form. A known quantity of this resin is accurately weighed in a glass container. To that $1 \%$ weight ratio of conducting polymer (polyaniline \& polypyrrole) are added and $1 \mathrm{ml}$ of tri amine hardener is added (the purpose of using tri amine hardener is that when epoxy is a thermosat polymer once it is mixed with hardener it acquire 3 dimensional network with rigid structure which cannot be broken by any means) and mixed slowly so that no air pockets are formed for 30 minute. The resting time should not exceed more than 30 minute else it will become hard mass and cannot be poured on acrylic sheet. So we should be cautious when watching out times as it should not increase more than 30 minute.

After 30 minute pour the gel on acrylic base material which are cut in dimension $3.4 \times 7.3 \mathrm{~cm}$ size and place it in desiccators for 24 hours. Desiccator containing desiccants used for preserving moist sensitive items cobalt chloride paper for another use. A usual use of desiccators is to safeguard chemicals which are hygroscopic or which respond with water from Evaporation. Desiccators is to either dry a chemical or keep a chemical form becoming wet from atmospheric humidity (wet air). During the above process solvent slowly evaporate living behind a coating of conductive composite.

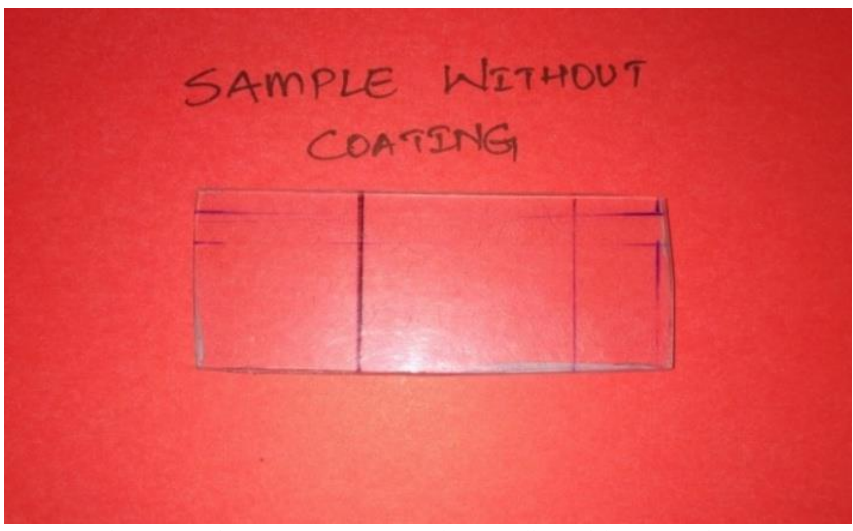

Figure 2: Size 3.4x7.3cm sample (acrylic) without coating

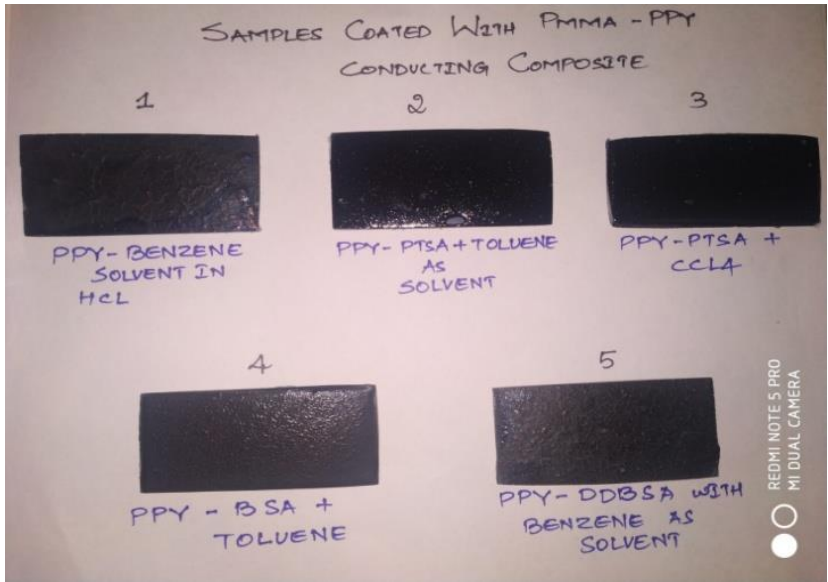

Figure 3: Samples coated with PMMA-PPY. 


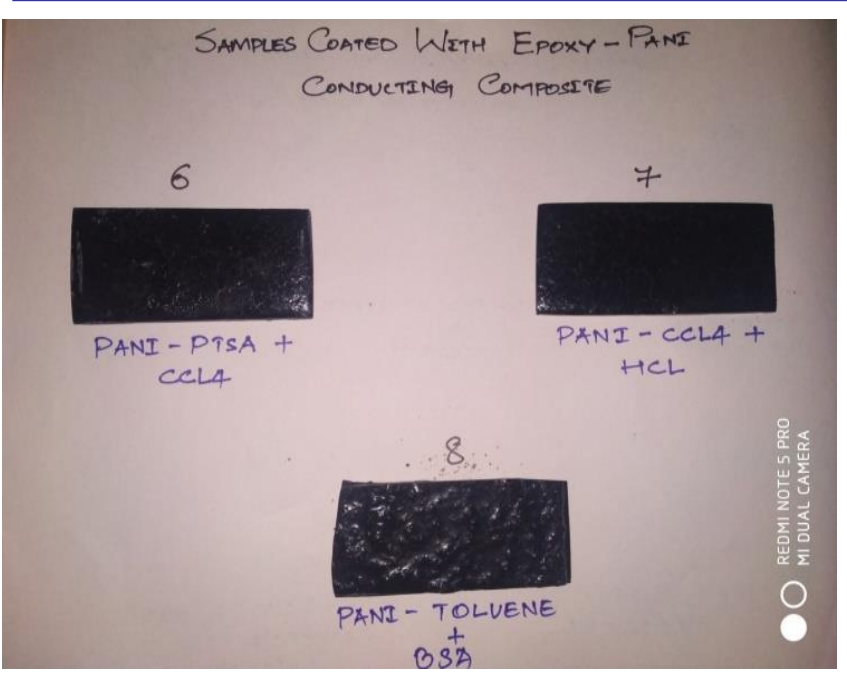

Figure 4: Samples coated with Epoxy-PANI.

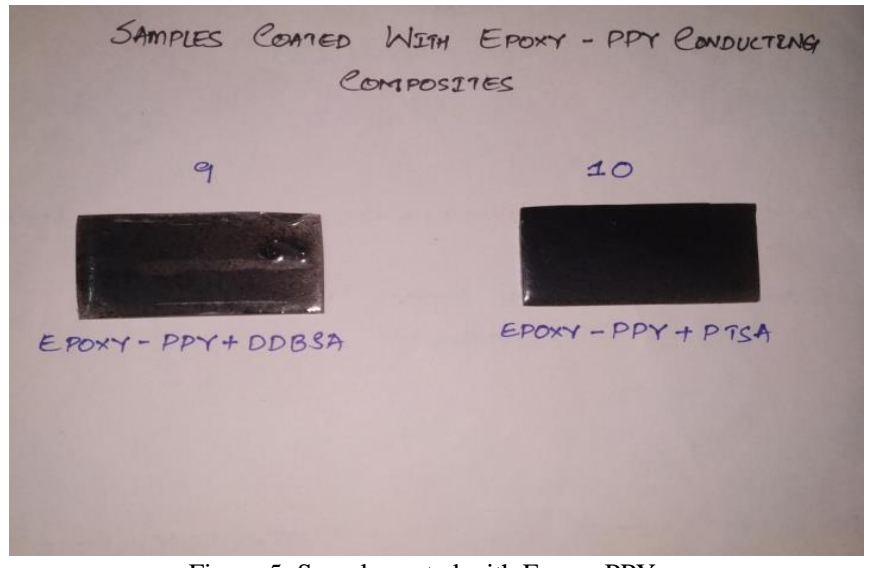

Figure 5: Sample coated with Epoxy-PPY.

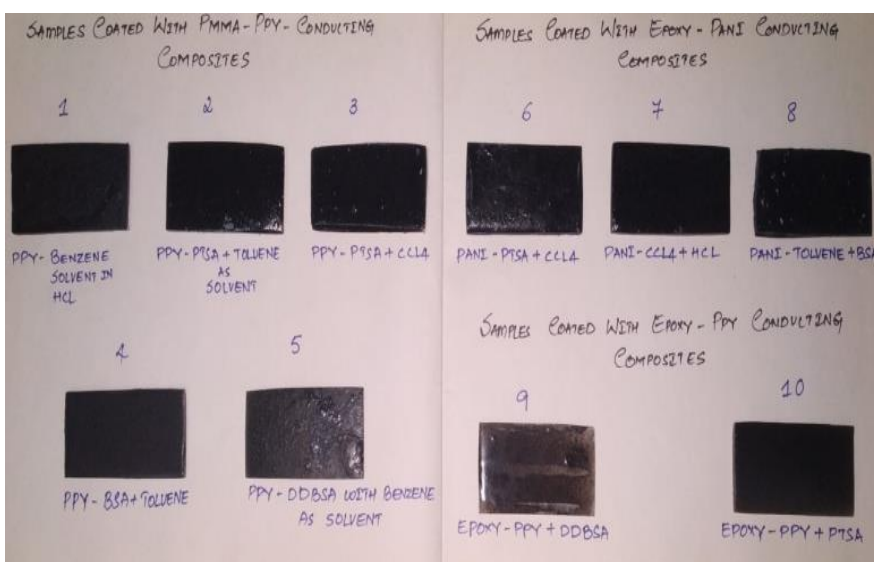

Figure 6: Samples coated with PMMA-PPY, Epoxy-PANI, Epoxy-PPY

\section{B. Instruements for Testing.}

Following instruments are required to carry out the testing:

1. Signal generator.

2. Rectangular wave guide.

3. Spectrum analyzer.

4. SignalVu-PC ${ }^{\mathrm{tm}}$ software.
5. PC/ laptop.

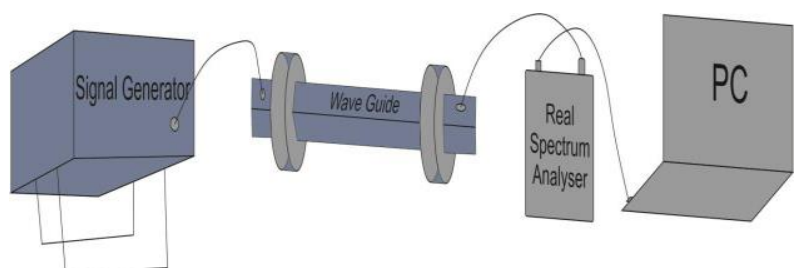

Figure 7: Schematic portrayal of electromagnetic shielding experimental setup.

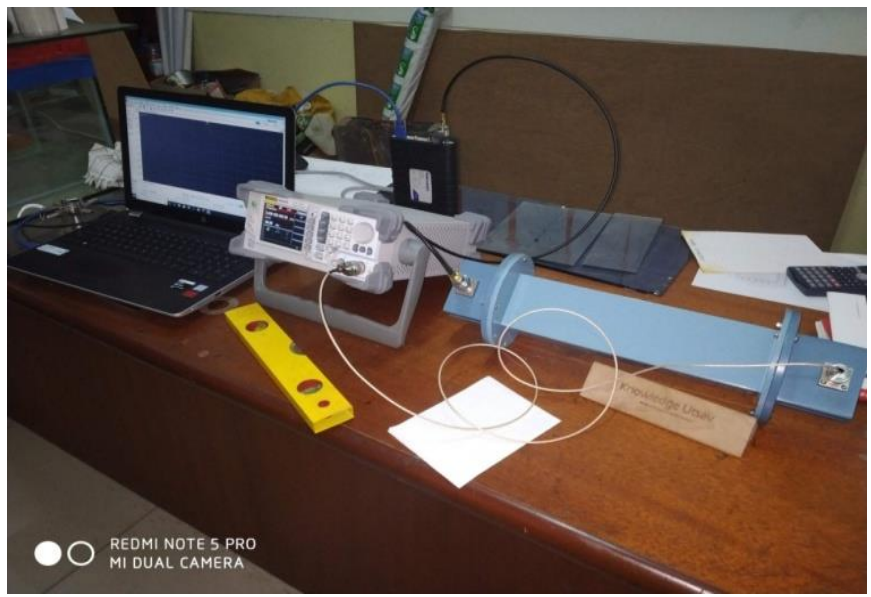

Figure 8: Actual electromagnetic shielding experimental setup.

In the following setup output of signal generator which measures frequency from $9 \mathrm{kHz}-3 \mathrm{GHz}$ which is connected to the input of a wave guide. Wave guide measure the frequency from the range $2-3 \mathrm{GHz}$. The output of wave guide is connected to the input of spectrum analyzer. Spectrum analyzer measure the frequency from the range $9 \mathrm{kHz}-6.2 \mathrm{GHz}$ The output of spectrum analyzer is connected to the laptop via USB cable. And laptop is connected to power supply.

In this experimental setup the sample is loaded in the wave guide at any end of the wave guide by removing top most part of waveguide using screw driver. Once you fix the sample inside the wave guide by securing it with screw using screw driver and you are ready to go.

\section{Testing of Samples}

- Power Loss without Sample.

To note down the reading without sample, wave guide is kept empty and the following reading of EMI in $\mathrm{dB}$ is noted down by varying frequency value from 2.1 to $3 \mathrm{GHz}$ in signal generator and PC. And the following table 1 shows power loss without sample and graph for power loss without sample is shown in graph 1 . 
Table 1: Power loss without sample (empty reading).

\begin{tabular}{|c|c|}
\hline $\begin{array}{c}\text { Frequency } \\
(\mathbf{G H z})\end{array}$ & $\begin{array}{c}\text { EMI SE } \\
(\mathbf{d B})\end{array}$ \\
\hline 2.1 & -64.9 \\
\hline 2.2 & -63.71 \\
\hline 2.3 & -62.03 \\
\hline 2.4 & -61.6 \\
\hline 2.5 & -64.72 \\
\hline 2.6 & -64.52 \\
\hline 2.7 & -65.84 \\
\hline 2.8 & -65.37 \\
\hline 2.9 & -67.36 \\
\hline 3 & -62.91 \\
\hline
\end{tabular}

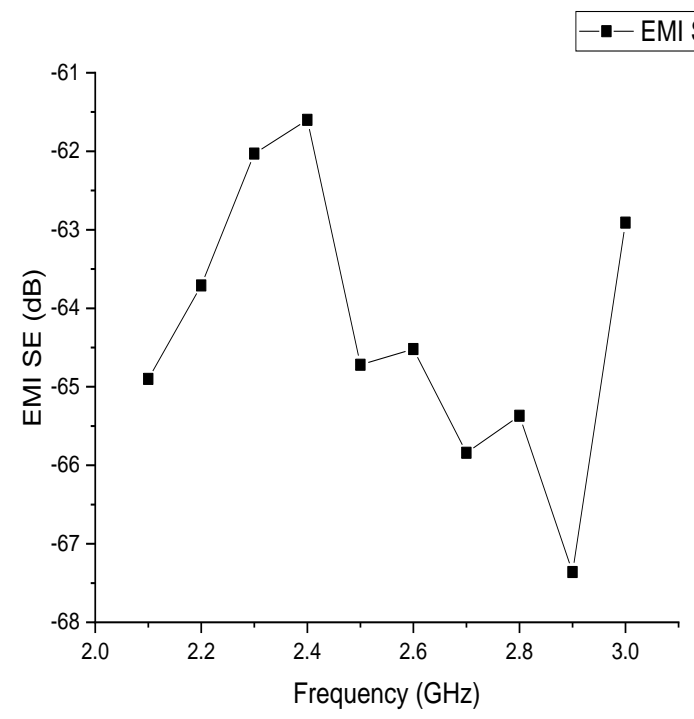

Graph 1: Power loss without sample.

- Power Loss with Samples.

Power loss with sample can be measured by placing samples in the wave guide. By varying frequency in the range $2-3 \mathrm{GHz}$ in signal generator and giving input frequency in $\mathrm{PC}$ then following power loss for the sample can be noted down in $\mathrm{dB}$ as shown in the table 2,3,4 and graph is plotted as shown in graph 2,3,4,5.

Table 2: Power loss with plain sample and PMMA-PPY coated sample 1 to 5 .

\begin{tabular}{|c|c|c|c|c|c|c|}
\cline { 2 - 7 } \multicolumn{1}{c|}{} & \multicolumn{7}{c|}{ EMI SE (dB) } \\
\hline F(GHz) & Plain & S-1 & S-2 & S-3 & S-4 & S-5 \\
\hline 2.1 & -61.63 & -64 & -66.35 & -64.96 & -63.42 & -64.9 \\
\hline 2.2 & -60.46 & -60.91 & -62.16 & -61.38 & -60.57 & -61.05 \\
\hline 2.3 & -58.09 & -57.91 & -59.98 & -58.29 & -57.43 & -57.91 \\
\hline 2.4 & -57.02 & -56.52 & -58.08 & -56.77 & -56.07 & -56.17 \\
\hline 2.5 & -58.21 & -57.96 & -59.86 & -58.25 & -57.49 & -57.74 \\
\hline 2.6 & -57.82 & -67.26 & -58.9 & -57.19 & -56.53 & -56.96 \\
\hline 2.7 & -59.48 & -59.54 & -60.01 & -59.66 & -58.79 & -59.26 \\
\hline 2.8 & -58.9 & -58.16 & -59.51 & -58.61 & -57.54 & -54.78 \\
\hline 2.9 & -63.24 & -63.32 & -64.52 & -63.35 & -62.36 & -62.77 \\
\hline 3 & -60.02 & -59.52 & -60.54 & -59.4 & -58.23 & -58.48 \\
\hline
\end{tabular}

\section{PLAIN}

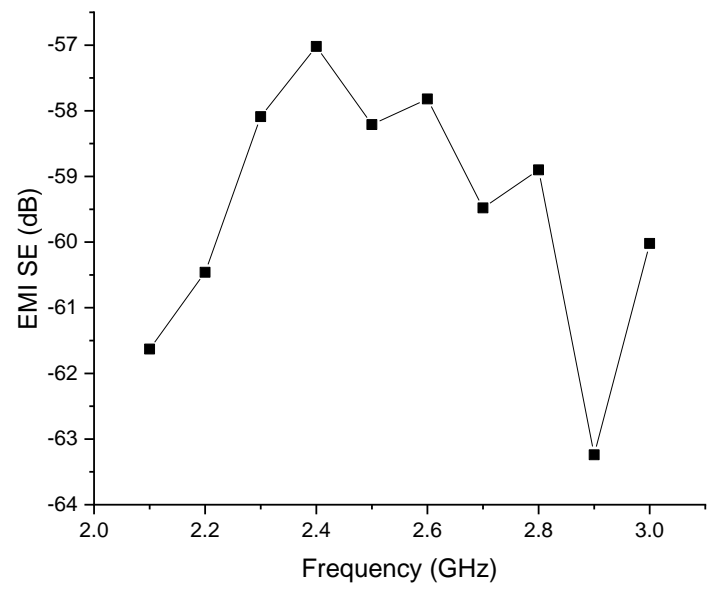

Graph 2: Power loss with plain sample.

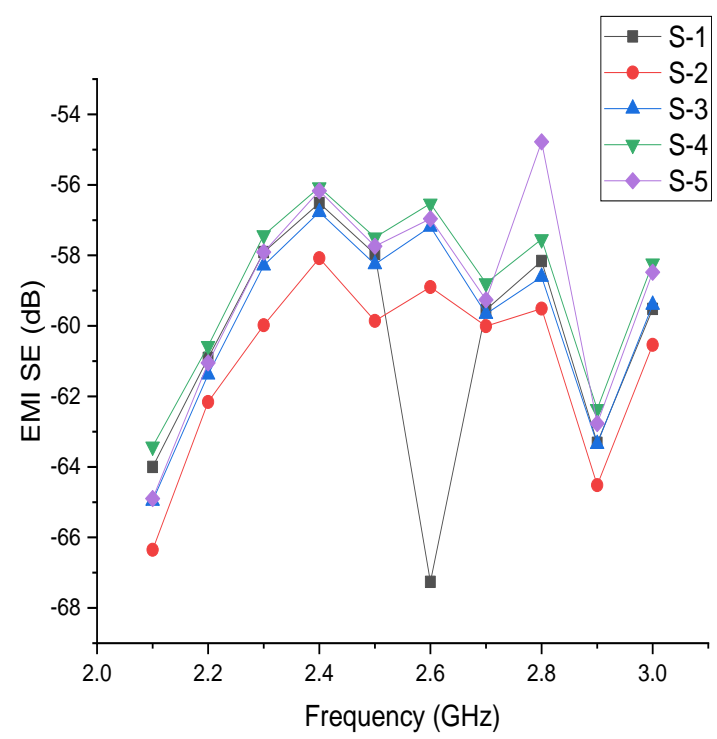

Graph 3: Power loss with sample from 1-5.

Table 3: Power Loss with Epoxy-PANI Sample 6 to 8

\begin{tabular}{|c|c|c|c|}
\cline { 2 - 4 } \multicolumn{1}{c|}{} & \multicolumn{3}{c|}{ EMI SE (dB) } \\
\hline F(GHz) & S-6 & S-7 & S-8 \\
\hline 2.1 & -65 & -66.36 & -64.41 \\
\hline 2.2 & -60.68 & -61.75 & -60.82 \\
\hline 2.3 & -58.08 & -58.87 & -57.91 \\
\hline 2.4 & -56.11 & -56.38 & -55.96 \\
\hline 2.5 & -57.79 & -58.52 & -57.69 \\
\hline 2.6 & -57.07 & -57.1 & -56.67 \\
\hline 2.7 & -59.19 & -59.8 & -59.02 \\
\hline 2.8 & -57.99 & -57.93 & -57.42 \\
\hline 2.9 & -62.81 & -63.38 & -62.61 \\
\hline 3 & -58.19 & -58.48 & -58.18 \\
\hline
\end{tabular}




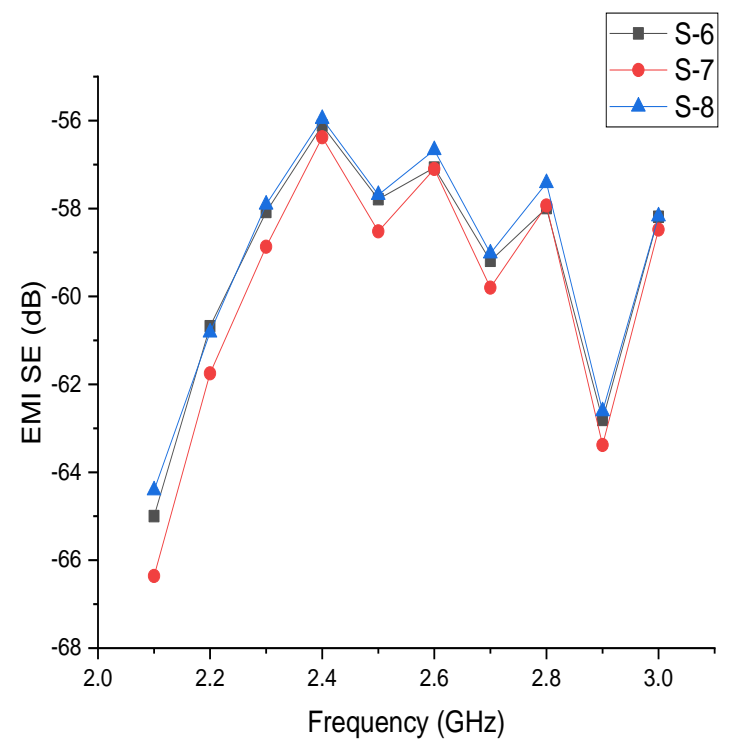

Graph 4: Power loss with sample from 6-8

Table 4: Power loss with EPOXY-PPY Sample 9 and 10

\begin{tabular}{|c|c|c|}
\cline { 2 - 3 } \multicolumn{1}{c|}{} & \multicolumn{2}{c|}{ EMI SE (dB) } \\
\hline F(GHz) & S-9 & S-10 \\
\hline 2.1 & -63.71 & -65 \\
\hline 2.2 & -60.62 & -61.22 \\
\hline 2.3 & -57.48 & -58.44 \\
\hline 2.4 & -55.85 & -56.74 \\
\hline 2.5 & -57.58 & -58.27 \\
\hline 2.6 & -56.42 & -57.36 \\
\hline 2.7 & -58.82 & -59.43 \\
\hline 2.8 & -57.42 & -58.14 \\
\hline 2.9 & -62.55 & -63.28 \\
\hline 3 & -58.12 & -59.11 \\
\hline
\end{tabular}

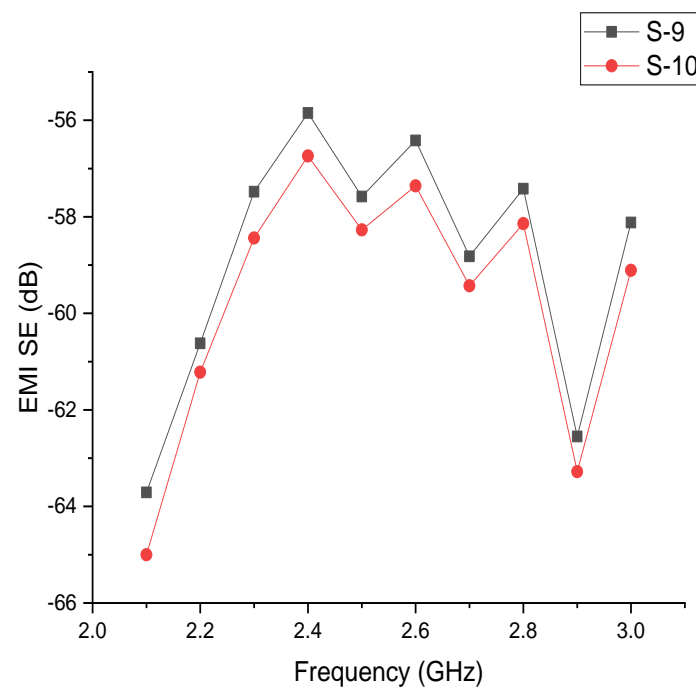

Graph 5: Power loss with sample 9 and 10.

- Power Loss Absorbed With Samples

To get the reading of power absorbed by the samples subtract the value of EMI SE (dB) which we got at the frequency of $2.1 \mathrm{GHz}$ to $3 \mathrm{GHz}$ sample inside the wave guide shown in the table 2, 3, 4, with the output value of EMI SE (dB) which we got at the frequency $2.1 \mathrm{GHz}$ to 3 $\mathrm{GHz}$ without sample inside the wave guide i.e empty wave guide as shown in table 1. Follow the same procedure with every sample from 2.1 to $3 \mathrm{GHz}$ Note down the power loss absorbed in $\mathrm{dB}$ by the each sample at particular frequency.

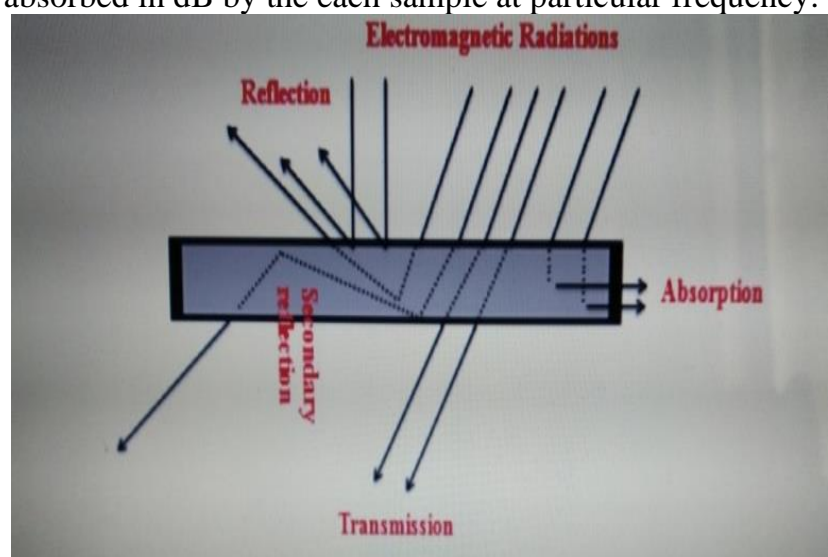

Figure 9: Schematic representation of electromagnetic shielding phenomena

Table 5: Power loss absorbed by plain sample and PMMA-PPY sample 1 to 5

\begin{tabular}{|c|c|c|c|c|c|c|}
\cline { 2 - 7 } \multicolumn{1}{c|}{} & \multicolumn{7}{c|}{ EMI SE (dB) } \\
\hline F(GHz) & Plain & S-1 & S-2 & S-3 & S-4 & S-5 \\
\hline 2.1 & 3.27 & 0.9 & -1.45 & -0.06 & 1.48 & 0 \\
\hline 2.2 & 3.25 & 2.8 & 1.55 & 2.33 & 3.14 & 2.66 \\
\hline 2.3 & 3.94 & 3.94 & 2.05 & 3.74 & 4.6 & 4.12 \\
\hline 2.4 & 4.58 & 4.58 & 5.08 & 4.83 & 5.53 & 5.43 \\
\hline 2.5 & 6.51 & 6.51 & 6.76 & 6.47 & 7.23 & 6.98 \\
\hline 2.6 & 6.7 & 6.7 & 5.62 & 7.33 & 7.99 & 7.56 \\
\hline 2.7 & 6.36 & 6.36 & 5.83 & 6.18 & 7.05 & 6.58 \\
\hline 2.8 & 6.47 & 6.47 & 5.86 & 6.76 & 7.83 & 10.59 \\
\hline 2.9 & 4.12 & 4.12 & 2.84 & 4.01 & 5 & 4.59 \\
\hline 3 & 2.89 & 2.89 & 2.37 & 3.51 & 4.68 & 4.43 \\
\hline
\end{tabular}

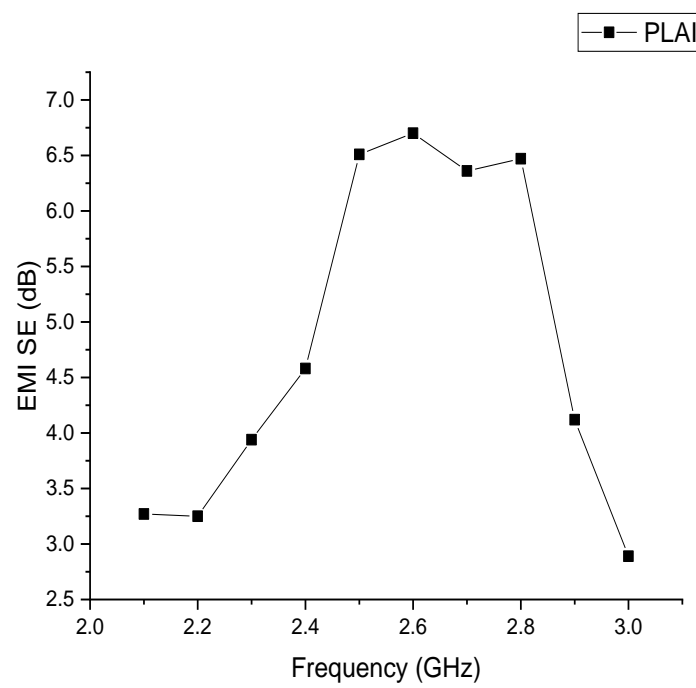

Graph 6: Power loss absorbed with plain sample 


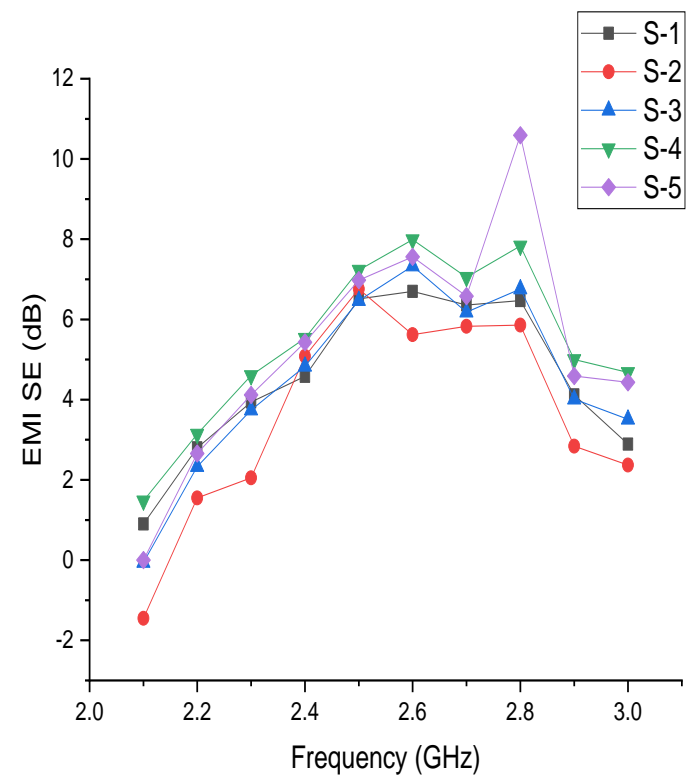

Graph 7: Power loss absorbed with sample from 1-5.

Table 6: Power Loss absorbed with EPoxy-PANI Sample 6 to 8

\begin{tabular}{|c|c|c|}
\cline { 2 - 3 } \multicolumn{1}{c|}{} & \multicolumn{2}{c|}{ EMI SE (dB) } \\
\hline F(GHz) & S-9 & S-10 \\
\hline 2.1 & 1.19 & -0.1 \\
\hline 2.2 & 3.09 & 2.49 \\
\hline 2.3 & 4.55 & 3.59 \\
\hline 2.4 & 5.75 & 4.86 \\
\hline 2.5 & 7.14 & 6.45 \\
\hline 2.6 & 8.1 & 7.16 \\
\hline 2.7 & 7.02 & 6.41 \\
\hline 2.8 & 7.95 & 7.23 \\
\hline 2.9 & 4.81 & 4.08 \\
\hline 3 & 4.79 & 3.8 \\
\hline
\end{tabular}

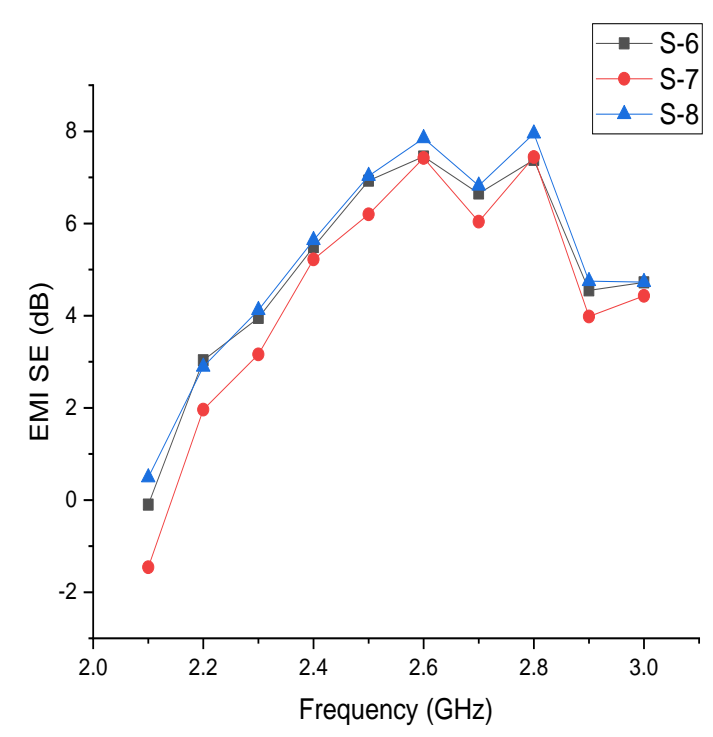

Graph 8: Power loss absorbed with sample from 6-8.
Table 7: Power Loss absorbed by Epoxy-PPY Sample 9\& 10

\begin{tabular}{|c|c|c|c|}
\cline { 2 - 4 } \multicolumn{1}{c|}{} & \multicolumn{3}{c|}{ EMI SE (dB) } \\
\hline F(GHz) & S-6 & S-7 & S-8 \\
\hline 2.1 & -0.1 & -1.46 & 0.49 \\
\hline 2.2 & 3.03 & 1.96 & 2.89 \\
\hline 2.3 & 3.95 & 3.16 & 4.12 \\
\hline 2.4 & 5.49 & 5.22 & 5.64 \\
\hline 2.5 & 6.93 & 6.2 & 7.03 \\
\hline 2.6 & 7.45 & 7.42 & 7.85 \\
\hline 2.7 & 6.65 & 6.04 & 6.82 \\
\hline 2.8 & 7.38 & 7.44 & 7.95 \\
\hline 2.9 & 4.55 & 3.98 & 4.75 \\
\hline 3 & 4.72 & 4.43 & 4.73 \\
\hline
\end{tabular}

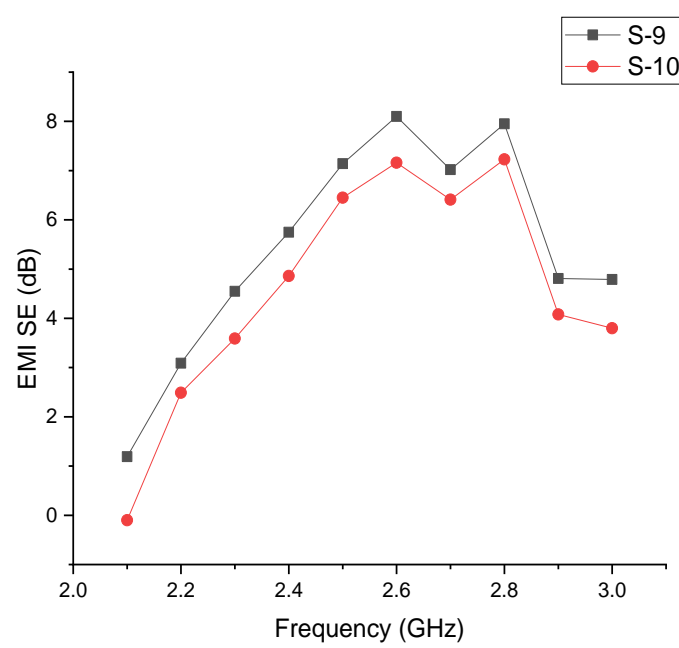

Graph 9: Power loss absorbed with sample 9 and 10

\section{RESULTS \& DISCUSSIONS.}

Checkout the samples which has the highest power loss absorption at the particular frequency, refer table 5,6,7 for each sample. Plot the graph and table as shown below.

Table 8: Samples with Highest Power Loss Absorption.

\begin{tabular}{|c|c|c|c|c|}
\hline $\begin{array}{c}\text { Sample } \\
\text { No }\end{array}$ & $\begin{array}{c}\text { EMI } \\
\text { SE } \\
(\mathbf{d B})\end{array}$ & $\begin{array}{c}\text { At } \\
\text { Frequency } \\
(\mathbf{G H z})\end{array}$ & $\begin{array}{c}\text { Conducting } \\
\text { Composites }\end{array}$ & Dopants \\
\hline 1 & 6.51 & 2.5 & PMMA-PPY & $\begin{array}{c}\text { Benzene } \\
\text { solvent in } \\
\text { HCL }\end{array}$ \\
\hline 2 & 6.76 & 2.7 & PMMA-PPY & $\begin{array}{c}\text { Toluene as } \\
\text { solvent }\end{array}$ \\
\hline 3 & 7.33 & 2.6 & PMMA-PPY & $\begin{array}{c}\text { PTSA + } \\
\text { CCL4 }\end{array}$ \\
\hline 4 & 7.99 & 2.6 & PMMA-PPY & $\begin{array}{c}\text { BSA + } \\
\text { Toluene as } \\
\text { solvent }\end{array}$ \\
\hline 5 & 10.59 & 2.8 & PMMA-PPY & $\begin{array}{c}\text { DDBSA }+ \\
\text { with } \\
\text { benzene as } \\
\text { solvent }\end{array}$ \\
\hline 6 & 7.45 & 2.6 & EPOXY-PANI & $\begin{array}{c}\text { PTSA + } \\
\text { CCL4 }\end{array}$ \\
\hline 7 & 7.44 & 2.8 & EPOXY-PANI & $\begin{array}{c}\text { CCL4 + } \\
\text { HCL }\end{array}$ \\
\hline 8 & 7.95 & 2.8 & EPOXY-PANI & $\begin{array}{c}\text { Toluene }+ \\
\text { BSA }\end{array}$ \\
\hline 9 & 7.95 & 2.8 & EPOXY-PPY & DDBSA \\
\hline 10 & 7.23 & 2.8 & EPOXY-PPY & PTSA \\
\hline
\end{tabular}




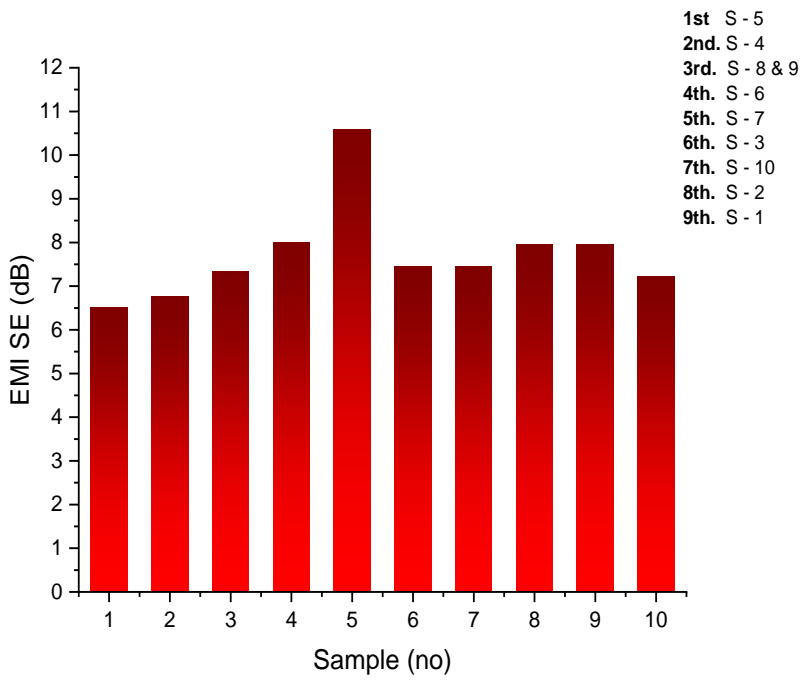

Graph 10: Samples with highest power loss absorption at particular frequency.

Above graph depicts the power loss by supplying microwave radiation through the rectangular wave guide with samples. It is shown in the figure 7,8 signal generator is connected to the wave guide and supplying microwave radiation through signal generator which is connected to the wave guide, the wave guide is further connected to the real spectrum analyzer which in turn connected to the PC. When microwave radiation falling on the samples three things can happen simultaneously, like absorption, reflection and transmission within the limitation of our experiment we could measure only power loss after passing through the samples.

The EMI shielding effectiveness shows more power loss absorbed by

\section{Sample 5 \\ 2. Sample 4 \\ 3. Sample 8 \& 9}

Further samples will be measured thoroughly using vector network analyzer, for the absorption, reflection and transmission of microwave radiation. Based on the experimental values, clearly indicates higher the absorption of microwave radiation in the range of 2 to $3 \mathrm{GHz}$. These samples used as electromagnetic radiation shielders in many technological applications. The following samples with highest power loss asbsorption is shown in table 8 and graph is plotted as shown in graph 10 .

\section{CONCLUSION}

Polypyrrole and polyaniline as a conducting polymers has been successfully synthesized by chemical oxidation technique with various dopants. Conducting composites are successfully prepared using host polymer matrix such as poly methyl methacrylate (PMMA) and Epoxy further composites are prepared using polyaniline (PANI) and polypyrrole (PPY) with various dopants. The composite mixture is successfully developed on acrylic sheets with the dimension $3.4 \times 7.4 \mathrm{~cm}$. Shielding effectiveness is measured in the range of $2.1 \mathrm{GHz}$ to $3 \mathrm{GHz}$ and the values are compared with empty reading in $\mathrm{dB}$. It is observed that at $2.5 \mathrm{GHz}$ microwave radiation has shown maximum shielding effectiveness in most of sample. The composites prepared using polypyrrole with dodecyl benzene sulfonic acid as a dopant has shown the highest shielding effectiveness i.e $10.59 \mathrm{~dB}$ when compared to other samples this is probably due to the high conductivity of polypyrrole with dopants when compared to polyaniline.

\section{REFERENCES}

[1] S. Geetha, K. K. Satheesh Kumar, Chepuri R. K. Rao, M. Vijayan, D. C. Trivedi,"EMI Shielding: Methods and MaterialsA Review," Journal of Applied Polymer Science, Vol. 112 2073-2086 (2009) Wiley Periodicals, Inc.Journal of Applied Polymer Science DOI 10.1002/app.

[2] Satish Chandra Gupta, Aditya Panwar, Sandhya Gupta, A.V. Singh "Electromagnetic Attenuation by Conducting Polymers Composites," 978-1-4577-1099-5/11/\$26.00 C2011 IEEE.

[3] Eva Hakansson, Andrew Amiet, Saeid Nahavandi, and Akif Kaynak "Electromagnetic Interference Shielding and Radiation Absorption in Thin Polypyrrole Films." European polymer journal, vol. 43, no. 1, pp. 205-213

[4] J1. Wojkiewicz, S.Fauveaux, JL.Miane "Dielectric Behavior And Shielding Properties Of Polyanilinie Composites," 2001 IEEE 7th International Conference on Solid Dielectrics, June 25-29,2001, Eindhoven, the Netherlands. 0-7803-6352-3/01/\$10.00 02001 IEEE.

[5] Ying Wu, Zhenyu Wang, Xu Liu, Xi Shen, Qingbin Zheng, Quan Xue, and Jang-Kyo Kim"Ultralight Graphene Foam/Conductive Polymer Composites for Exceptional EMI shielding" DOI: 10.1021/acsami.7b01017 ACS Appl. Mater. Interfaces 2017, 9, 9059-9069.

[6] Xiangcheng Luo, D.D.L.Chung "Electromagnetic interference using carbon-fiber carbon-Matrix and polymermatrix composites," 1359-8368/99/\$@1999 Elsevier All right reserved PII: S1359-8368(98)00065-1.

[7] Furnishiro Tsuda, Hiroshi Ono, Shinichi Shinohara, Risaburo Sato. "Effects of Installing Magnetic-Polymer-Composites Layers on Transmission Line to Reduce Conducted Electromagnetic Noise." 0-7803-5677-2/00/\$10.0 @2000 IEEE

[8] Mustafa Ozkok, Seven Lamprecht, Eckart Klusmann, Henning Hubner. "Adjustable EMI Electrolytic Packages Realised by Electrolytic Plate,” 2019 IEE 10.1109/ICSJ47124.2019.8998721.

[9] C. D. Xu, K. W. E. Cheng, Y. Zou, H. F. Ho, X. L. Wang. “A Polymer Bonded Gridded Box EMI Shielding Method Based on FEM for High Speed Railway," 2016 ISEEE 10.1109/EENG.2016.7846359.

[10] R. B. Schulz, V.C. Plantz, D. R. Brush, "Shielding Theory and Practice," IEEE Vol. 30, pp.187- 201,1988.

[11] Francesco de Paulis, Muhammet Hilmi Nisanci, Antonio Orlandi, Marina Y. Koledintseva, James L. Drewniak, "Design of Homogeneous and Composite Materials From Shielding Effectiveness Specification," IEEE Vol.56. no.2, pp.343-351, Apr.2014.

[12] N. F. Colaneri. L.W. Schacklette, "EMI Shielding Measurements of Conductive Polymer Blends,"IEEE Vol.41 Issue:2, Apr 1995. 